\title{
Crystal and Molecular Structures of N-benzyl-C-(2-pyridyl) nitrone and its $\mathrm{ZnBr}_{2}$ Complex. A Study of Their Reactivity ${ }^{\dagger}$.
}

\author{
Pedro Merino*,1, Sonia Anoro, Elena Cerrada ${ }^{2}$, Mariano Laguna², Ana Moreno² and Tomas \\ Tejero'.
}

1 Laboratorio de Síntesis Asimétrica, Departamento de Quimica Organica, Facultad de Ciencias, Universidad de Zaragoza, E-50009 Zaragoza, Aragon, Spain, Fax: +34 976 762075; URL: http://wzar.unizar.es/acad/fac/cie/quiorg/asimetrica/mtm.html

${ }^{2}$ Departamento de Quimica Inorganica, Instituto de Ciencia de Materiales de Aragon, Universidad de Zaragoza-CSIC, E-50009 Zaragoza, Aragon, Spain.

$\dagger$ This paper was at the Fourth Electronic Conference on Synthetic Organic Chemistry (ECSOC-4), September 1-30, 2000. Paper A0008.

* Author to whom correspondence should be addressed; E-mail: pmerino@posta.unizar.es

Received: 18 January 2001/ Accepted: 22 January 2001 / Published: 28 February 2001

\begin{abstract}
The $\mathrm{ZnBr}_{2}$ complex of the title compound has been studied by both structural and theoretical methods. Similar reactivities have been observed for the nitrone alone and the complex in 1,3-dipolar cycloadditions and nucleophilic additions.
\end{abstract}

Keywords: Nitrone complexes, Dipolar cycloadditions, Theoretical calculations.

\section{Introduction}

Lewis acid modulated reactions play a very important role in organic synthesis as they provide versatile intermediates, sometimes dictating the stereochemistry of the products [1]. Nitrones are substrates rather sensitive to Lewis-acid modulation in nucleophilic additions to chiral nitrones as we have amply demonstrated during the last few years [2]. For instance, it has been demonstrated in our laboratory that by employing either $\mathrm{ZnBr}_{2}$ or $\mathrm{Et}_{2} \mathrm{AlCl}$, one can produce hydroxylamines with either syn or anti stereochemistry (with respect to the alfa group), respectively [3]. 
1,3-Dipolar cycloaddition reactions with nitrones are also susceptible to influence by the presence of Lewis acids. In fact, Lewis acids catalyzed nitrone cycloadditions have been extensively studied [4]. Kanemasa and Tsuruoka have suggested the participation of nitrone- $\mathrm{MgBr}_{2}$ complexes in some cycloaddition reactions with allylic alcohols [5]. The scope and limitations of chiral $\mathrm{Mg}$ (II) and $\mathrm{Cu}$ (II) complexes on the selectivity of cycloaddition of nitrones with alkenes have been studied by Jorgensen and coworkers [6]. Activation of nitrones towards cycloadditions with electron-rich alkenes by chiral Lewis acids have also been reported [7].

In the context of cycloaddition chemistry, we have recently reported the 1,3-dipolar cycloaddition of several hetaryl nitrones 1-5 with both electron-rich [8] and electron-deficient alkenes [9]. The asymmetric version of the cycloaddition reaction between C-(2-furyl)-N-benzyl nitrone $\mathbf{1}$ and acrylates has been used in the preparation of various protected derivatives of 4-hydroxy-pyroglutamic acids of synthetic utility [10].

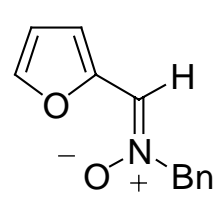

1<smiles>[O-][N+](=Cc1ccccn1)c1ccccc1</smiles>

2<smiles>[O-][N+](=Cc1nccs1)c1ccccn1</smiles>

3<smiles>[O-][N+](=Cc1cccs1)c1ccccc1</smiles>

4<smiles>[O-][N+](=Cc1cccnc1)c1ccccc1</smiles>

5

With the aim of modulating the reactivity of hetaryl nitrones 1-5 we have started a project directed towoards an understanding of the properties of Lewis acid complexes with compounds 1-5. Stable complexes of nitrones have already been studied. Nitrone complexes of iron have been fully characterized and their acidic hydrolysis studied by Pierre and coworkers [11]. The same authors have also reported the electrochemical reduction of such complexes [12]. Several tin (IV) complexes with nitrones giving pentacoordinated metal compounds have been prepared [13]. Crist and coworkers [14] have prepared and characterized complexes of N-tert-butyl-C-(2-pyridyl) nitrone with $\mathrm{Cu}(\mathrm{II}), \mathrm{Mn}(\mathrm{II})$, $\mathrm{Co}(\mathrm{II}), \mathrm{Ni}(\mathrm{II}), \mathrm{Fe}(\mathrm{II})$ and $\mathrm{Fe}(\mathrm{III})$. The X-ray structures of some complexes have also been determined [15]. Boron chelates with some particular aryl nitrones have also been described [16].

In this communication we describe the structural and theoretical studies of both (Z)-N-benzyl-C-(2pyridyl) nitrone and its $\mathrm{ZnBr}_{2}$ complex. Additionally, we also compare the reactivity of the nitrone alone and the isolated complex in cycloaddition reactions and a nucleophilic addition reaction.

\section{Synthesis and Structural Analysis}

The N-benzyl-C-(2-pyridyl) nitrone 2 was prepared by condensation of pyridine-2-carbaldehyde [17] and N-benzylhydroxylamine [18] following our previously reported procedure [19]. Compound 2 was a crystalline stable product and showed a Z-configuration as demonstrated by NOE experiments and X-ray crystallography. Transparent blocks of $\mathbf{2}$ were grown at room temperature by slow evaporation of a 1:1 hexane/EtOAc mixture. X-ray diffraction data were obtained at $173 \mathrm{~K}$ and the structure is given in Figure 1. Selected data are given in Table 1. 
The reaction of 2 with $\mathrm{ZnBr}_{2}$ in acetone for $1 \mathrm{~h}$ gave the crystalline chelate $\mathbf{6}$ after precipitation with diethyl ether (Scheme 1). This compound displayed a signal for the azomethine proton at $\delta 5.40 \mathrm{ppm}$ in contrast to the signal at $\delta 5.19 \mathrm{ppm}$ displayed by nitrone 2 for the same proton. This result indicated the different orientation of the nitrone group induced by the complexation with the Lewis acid.

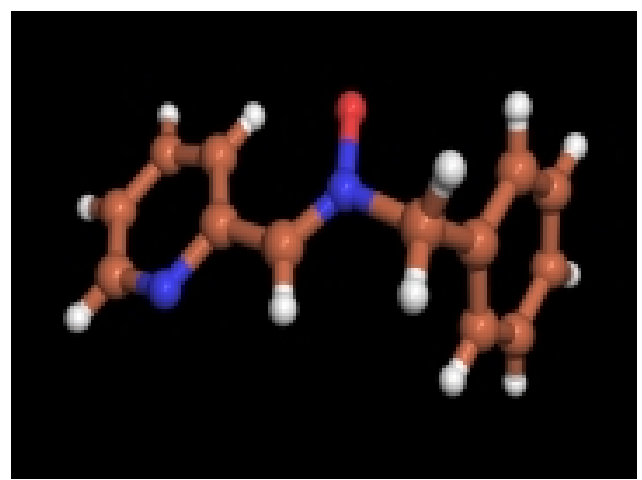

Figure 1. X-ray structure of nitrone 2

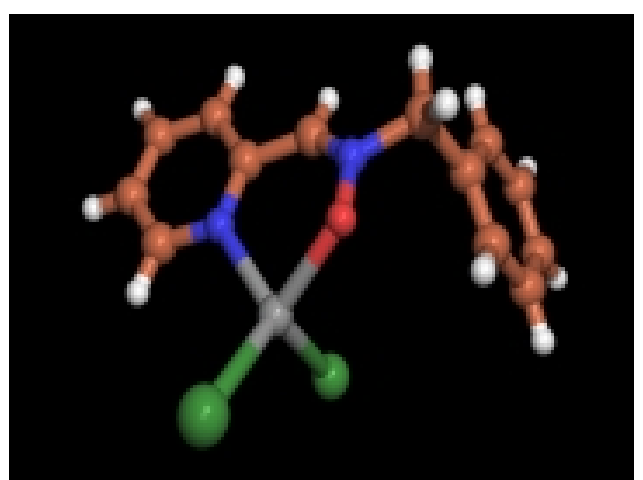

Figure 2. X-ray structure of complex 6

The complex 6 was crystallized as transparent blocks suitable for X-ray analysis from a 1:1 $\mathrm{CH}_{2} \mathrm{Cl}_{2}$ /hexane mixture. The X-ray diffraction data were obtained at $243 \mathrm{~K}$ (due to some instability of the crystal at lower temperatures) and the structure is given in Figure 2. This structure provided an opportunity to compare the structure of $\mathbf{6}$ with $\mathbf{2}$. In fact, the features of the solid-state geometry of $\mathbf{6}$ summarized in Table 1, are discussed in comparison with the values for $\mathbf{2}$.<smiles>[O-][N+](=Cc1ccccn1)c1ccccc1</smiles>

2

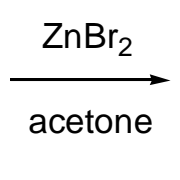

Scheme 1.

A coplanarity is seen, as in other hetaryl nitrones [20], between the planes of the heterocycle moiety and the nitrone function in both the nitrone alone and the chelate with $\mathrm{ZnBr}_{2}$. As expected, formation of the complex resulted in some bond length and bond angle differences between 2 and 6 (Table 1). It is worthwhile noting the change of the N2-C3-C4-N5 dihedral angle as a consequence of the formation of the chelate. In the complex the metal atom adopts an almost tetrahedral disposition the bond angles with bromine atoms being larger than those with nitrogen and oxygen atoms.

\section{X-ray diffraction data}

Selected X-ray acquisition data and crystallographic data for compounds $\mathbf{2}$ and $\mathbf{6}$ appear in Table 1 and Table 2, respectively. The final unit-cell parameters were obtained by least squares on the settings angles for 39 reflections with $\theta_{\min / \max }=9.49-24.75 \mathrm{deg}$. for 2 and 32 reflections with $\theta_{\min / \max }=10.35$ $24.56 \mathrm{deg}$. for 6. Intensity data were measured on a Siemens P4 diffractometer using the $\omega-2 \theta$ scan 
technique. The structures were solved by direct methods and all non-hydrogen atoms were refined anisotropically. The hydrogen atoms were located at calculated positions.

Table 1. Selected X-ray acquisition data for 2 and $\mathbf{6}$.

\begin{tabular}{|c|c|c|}
\hline & 2 & 6 \\
\hline Formula & $\mathrm{C}_{13} \mathrm{H}_{12} \mathrm{~N}_{2} \mathrm{O}$ & $\mathrm{C}_{13} \mathrm{H}_{12} \mathrm{Br}_{2} \mathrm{~N}_{2} \mathrm{OZn}$ \\
\hline FW & 212.25 & 437.44 \\
\hline Crystal system & orthorhombic & triclinic \\
\hline Space group & Pbcn & P-1 \\
\hline $\mathrm{a}(\AA)$ & $11.033(5)$ & $7.303(2)$ \\
\hline $\mathrm{b}(\AA)$ & $11.107(5)$ & $8.135(3)$ \\
\hline$c(\AA)$ & $17.414(5)$ & $12.970(6)$ \\
\hline$\alpha($ deg.) & 90 & $87.01(3)$ \\
\hline$\beta$ (deg.) & 90 & $80.56(3)$ \\
\hline$\gamma($ deg. $)$ & 90 & $84.60(3)$ \\
\hline$V\left(\AA^{3}\right)$ & $2134.0(15)$ & $756.2(5)$ \\
\hline $\mathrm{Z}$ & 8 & 2 \\
\hline$\rho_{\text {calc }}\left(\mathrm{g} / \mathrm{cm}^{3}\right)$ & 1.321 & 1.921 \\
\hline $\mathrm{F}(000)$ & 896 & 424 \\
\hline$\mu\left(\mathrm{Mo}-\mathrm{K}_{\alpha}\right), \mathrm{cm}-1$ & 0.086 & 6.900 \\
\hline crystal size, $\mathrm{mm}$ & $0.38 \times 0.20 \times 0.16$ & $0.24 \times 0.10 \times 0.08$ \\
\hline measurement $\mathrm{T}(\mathrm{K})$ & $173(2)$ & $243(2)$ \\
\hline$\theta_{\max }($ deg.) & 25.11 & 25.0 \\
\hline crystal decay (\%) & 6.86 & 15.4 \\
\hline total reflections & 2446 & 5169 \\
\hline total unique reflections & 1886 & 2628 \\
\hline $\mathrm{R}_{\text {merge }}$ & 0.072 & 0.097 \\
\hline reflections $\mathrm{I}>2 \sigma(\mathrm{I})$ & 1083 & 1333 \\
\hline No. parameters & 147 & 174 \\
\hline $\mathrm{R}$ & 0.0474 & 0.1007 \\
\hline $\mathrm{R}_{\mathrm{w}}$ & 0.0847 & 0.2432 \\
\hline $\operatorname{GoF}(\mathrm{S})$ & 1.084 & 1.162 \\
\hline \multicolumn{3}{|c|}{$\begin{array}{l}\text { Siemens P4 diffractometer. Mo-Ka radiation }(\lambda=0.71609 \AA) \text {, normal focus } \\
\text { sealed tube, graphite monochromator. Values given for R, Rw and GoF are } \\
\text { based on total unique reflections. Computing data collections: Siemens } \\
\text { XSCANS [21]. Structure solution: SIR-97 [22]. Structure refinement: } \\
\text { SHELXL-97 [23]. Molecular Graphics: PovChem v 2.1 [24] }\end{array}$} \\
\hline
\end{tabular}




\section{Theoretical Calculations}

In order to assess the various factors contributing to the structural differences between $\mathbf{2}$ and $\mathbf{6}$ we have carried out ab initio energy calculations. The optimized structures for $\mathbf{2}$ and $\mathbf{6}$ are shown in Figures 3 and 4.

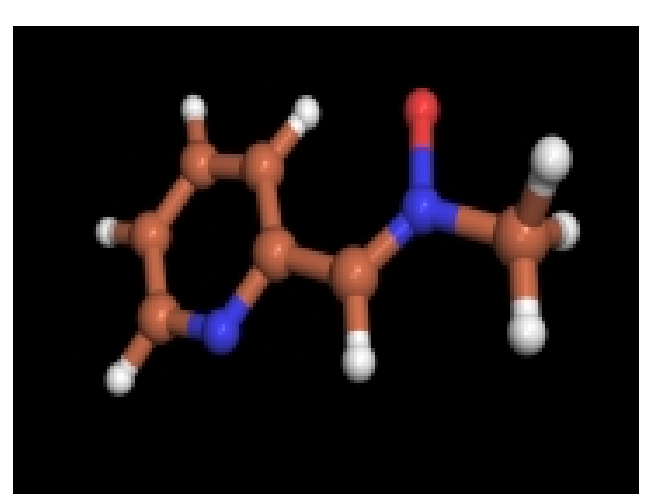

Figure 3. Optimized structure $(\mathrm{HF} / 3-21 \mathrm{G})$ for 2

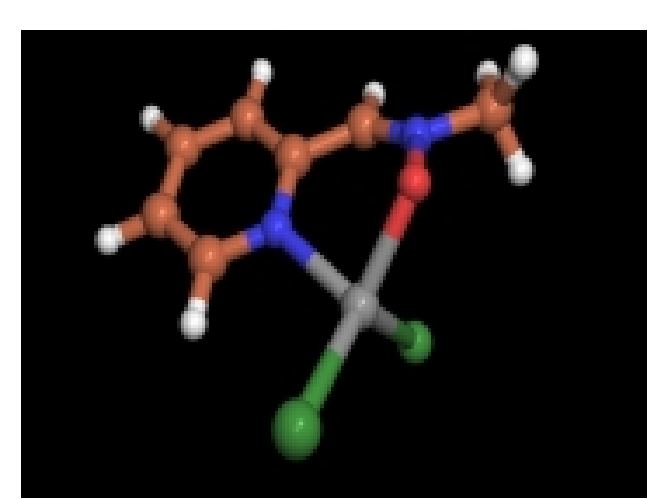

Figure 4. Optimized structure $(\mathrm{HF} / 3-21 \mathrm{G})$ for 6

The molecular structures determined using ab initio calculations agree with those observed in the crystalline state although some minor differences were observed. For instance, theoretical calculations gave longer O1-N2 bonds and shorter N2-C3 bonds than those found in crystalline state, presumably due to the consideration of resonance for the nitrone function. Nevertheless, the modeled structures showed a good overlap with the X-ray structures (Figures 5 and 6).

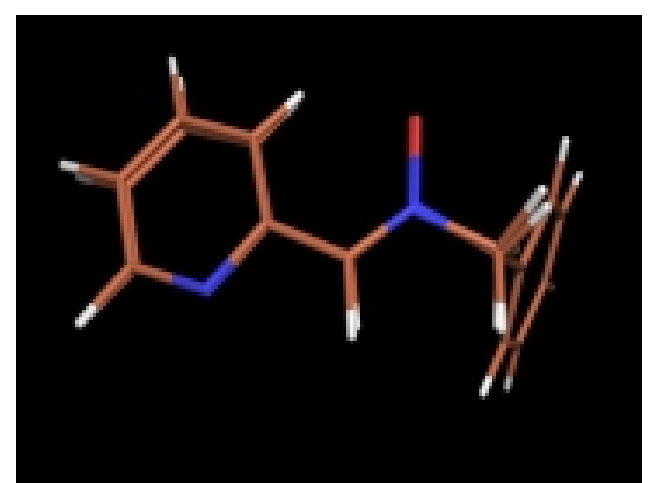

Figure 5. Comparison of the modeled structure of nitrone 2 with the X-ray structure.

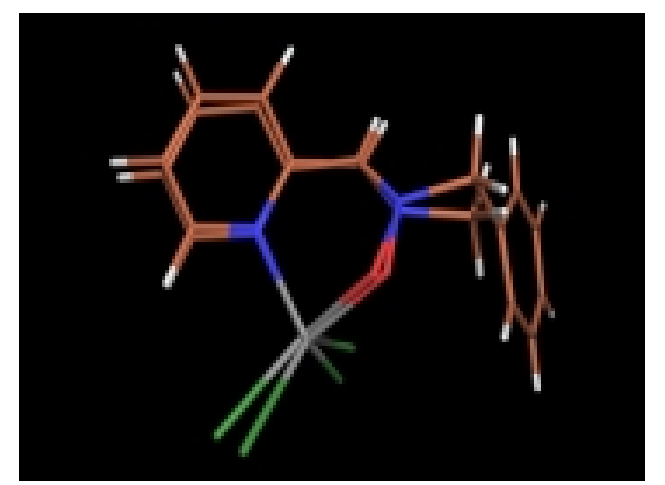

Figure 6. Comparison of the modeled structure of complex 6 with the X-ray structure.

\section{Ab initio calculations}

Calculated structures were optimized at HF/3-21G level using Gaussian98 [25]. All internal coordinates were free. In both $\mathbf{2}$ and $\mathbf{6}$ the benzyl group has been replaced for a methyl group, and in the case of $\mathbf{6}$ the $\mathrm{Br}$ atoms have been replaced by $\mathrm{Cl}$ atoms. The X-ray data were used (after replacement of the indicated groups) to generate guessed structures which were pre-optimized at semiempirical level (PM3) using MOPAC97 as implemented in CS ChemOffice [26]. In the case of 
the nitrone alone a complete conformational analysis has been carried out in order to determine the preferred orientation of the nitrone function with respect to the pyridine ring.

Table 2. Selected bond lengths $(\AA)$, bond angles $\left(^{\circ}\right)$ and dihedral angles $\left(^{\circ}\right)$ for 2 and $\mathbf{6}$.

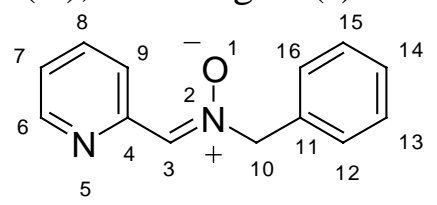

numbering scheme

\begin{tabular}{|c|c|c|c|c|}
\hline & \multirow{2}{*}{\multicolumn{2}{|c|}{ Nitrone 2}} & \multirow{2}{*}{\multicolumn{2}{|c|}{ Complex 6}} \\
\hline & & & & \\
\hline & X-ray data & $\mathrm{HF} / 3-21 \mathrm{G}$ & X-ray data & $\mathrm{HF} / 3-21 \mathrm{G}$ \\
\hline \multicolumn{5}{|l|}{ bond lenghts } \\
\hline O1-N2 & 1.299 & 1.383 & 1.396 & 1.326 \\
\hline $\mathrm{N} 2-\mathrm{C} 3$ & 1.300 & 1.268 & 1.261 & 1.228 \\
\hline $\mathrm{C} 3-\mathrm{C} 4$ & 1.451 & 1.458 & 1.469 & 1.501 \\
\hline C4-N5 & 1.365 & 1.337 & 1.318 & 1.318 \\
\hline $\mathrm{N} 2-\mathrm{C} 10$ & 1.488 & 1.472 & 1.477 & 1.500 \\
\hline $\mathrm{O} 1-\mathrm{Zn}$ & -------- & -------- & 1.993 & 1.930 \\
\hline $\mathrm{N} 5-\mathrm{Zn}$ & -------- & -------- & 2.055 & 2.029 \\
\hline $\mathrm{Zn}-\mathrm{Br} 1$ & -------- & -------- & 2.321 & 2.287 \\
\hline $\mathrm{Zn}-\mathrm{Br} 2$ & - & - & 2.357 & 2.333 \\
\hline \multicolumn{5}{|l|}{ bond angles } \\
\hline O1-N2-C3 & 126.1 & 125.6 & 127.3 & 123.5 \\
\hline $\mathrm{N} 2-\mathrm{C} 3-\mathrm{C} 4$ & 126.3 & 126.4 & 129.8 & 125.7 \\
\hline $\mathrm{C} 3-\mathrm{C} 4-\mathrm{N} 5$ & 113.2 & 113.8 & 118.6 & 119.6 \\
\hline O1-N2-C10 & 114.4 & 111.2 & 111.1 & 111.2 \\
\hline C3-N2-C10 & 119.5 & 123.2 & 121.0 & 125.3 \\
\hline O1-Zn-N5 & - & - & 89.7 & 87.5 \\
\hline $\mathrm{N} 2-\mathrm{O} 1-\mathrm{Zn}$ & -------- & -------- & 118.1 & 111.1 \\
\hline N5-Zn-Br1 & -------- & -------- & 108.1 & 105.3 \\
\hline $\mathrm{O} 1-\mathrm{Zn}-\mathrm{Br} 2$ & -------- & -------- & 113.7 & 126.1 \\
\hline \multicolumn{5}{|l|}{ dihedral angles } \\
\hline O1-N2-C3-C4 & 3.1 & 0.0 & 2.6 & 2.9 \\
\hline N2-C3-C4-N5 & 175.6 & 180.0 & 13.0 & 23.7 \\
\hline O1-N2-C10-C11 & 112.6 & ------- & ------- & 85.0 \\
\hline N2-O1-Zn-N5 & -------- & -------- & 122.8 & 141.5 \\
\hline O1-Zn-N5-C4 & -------- & -------- & 37.2 & 30.7 \\
\hline
\end{tabular}




\section{Reactivity}

The reactivity of the complex was studied by condensing it with the dipolarophiles vinyl acetate 7 (Scheme 2) and methyl acrylate 9 (Scheme 3). To this respect we have recently reported [8] the reaction between nitrones 1-5 and vinyl acetate 7 to give the corresponding isoxazolidines. It might be expected a difference of reactivity between $\mathbf{2}$ and $\mathbf{6}$. However, only slight differences in both reactivity and selectivity were found. Data for the reactivity with the dipolarophiles are summarized in Table 3. The results of the same reaction with nitrone $\mathbf{2}$ are also given for comparison.<smiles>C=COC(C)=O</smiles>

\section{Scheme 2.}<smiles>C=CC(C)=[C+]C1=[N+](Br)[Ge](Br)(Br)O[N+]1Cc1ccccn1</smiles>

6<smiles>COC1CC(c2ccccn2)N(Cc2ccccc2)O1</smiles>

$10 a$<smiles>CO[C@H]1C[C@@H](c2ccccn2)N(Cc2ccccc2)O1</smiles>

$10 b$<smiles>COC(=O)C1CON(Cc2ccccc2)[C@H]1c1ccccn1</smiles>

10c

Scheme 3.

In both cycloadditions with vinyl acetate and allyl alcohol only the corresponding 3,5-regioisomers were detected, the cis adduct being obtained preferentially.

Table 3. Reactivity of nitrone 2 and complex 6 in 1,3-dipolar cycloadditions

\begin{tabular}{|c|c|c|c|c|}
\hline 1,3-Dipole & dipolarophile $^{\mathrm{b}}$ & time & ${\text { cis }: \text { trans }^{\mathrm{c}}}$ & yield (\%) $^{(\%)}$ \\
\hline $\mathbf{2}$ & $\mathbf{7}$ & $168 \mathrm{~h}$ & $85: 15$ & 93 \\
\hline $\mathbf{2}$ & $\mathbf{9}$ & $72 \mathrm{~h}$ & $23: 77^{\mathrm{d}}$ & 93 \\
\hline $\mathbf{6}$ & $\mathbf{7}$ & $168 \mathrm{~h}$ & $89: 11$ & 92 \\
\hline $\mathbf{6}$ & $\mathbf{9}$ & $72 \mathrm{~h}$ & $27: 73^{\mathrm{e}}$ & 89 \\
\hline
\end{tabular}

${ }^{a}$ All reactions were conducted in acetone at reflux. ${ }^{b} 20$ eq. were used. ${ }^{c}$ The relative stereochemistry was determined by nOe experiments. ${ }^{\mathrm{d}}$ a $10 \%$ of compound 10c was obtained. ${ }^{\mathrm{e}}$ a $13 \%$ of compound $10 \mathrm{c}$ was obtained.

In the reaction with methyl acrylate, however, the trans adduct was obtained as the major compound. In this reaction one of the 3,4-regioisomers was also observed, although as a minor compound. 
These results are in good agreement with previous data relating to the cycloaddition reactions of nitrones with electron-rich and electron-poor alkenes [8,9]. According to these data the 3,5isoxazolidines are the major compounds and an exo-approach leading to cis adducts is preferred with electron-rich alkenes whereas the endo-approach leading to trans adducts is that preferred with electron-poor dipolarophiles.

We also compared the reactivity of the nitrone $\mathbf{2}$ and the complex $\mathbf{6}$ in a nucleophilic addition reaction. Thus, the nucleophilic addition of phenylmagnesium bromide, according to our previously described protocol [3c], led to the corresponding hydroxylamine. In this type of reaction no substantial differences were observed between the nitrone alone and the complex, yet (Scheme 4).<smiles>[O-][N+](Br)=Cc1ccccn1</smiles>

2

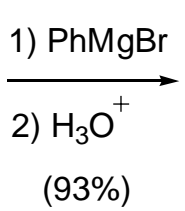

$(93 \%)$<smiles>ON(Cc1ccccc1)C(c1ccccc1)c1ccccn1</smiles>

11

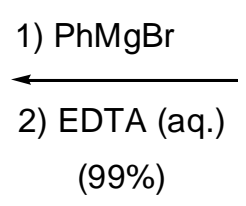

$(99 \%)$

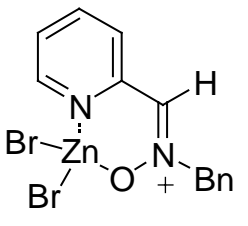

6

\section{Scheme 4.}

\section{Conclusions}

In summary, this preliminary result showed the possibility of using complexed nitrones as suitable 1,3-dipoles in cycloaddition reactions. Similar structures were found in the crystal structure and by the ab initio calculations both for nitrone 2 and $\mathrm{ZnBr}_{2}$-complex $\mathbf{6}$. The reactivity of those compounds were compared by condensing them with several dipolarophiles and a Grignard reagent. Only slight differences of reactivity were observed between the nitrone alone and the complex. Nevertheless, such a similar reactivity is rather promising since it open a window to the use of chiral auxiliaries linked to the metal atom (instead halogen atoms) in order to induce asymmetry in the studied reactions. Further investigations addressing this concept are now in progress in our laboratories.

\section{Acknowledgements}

The authors gratefully acknowledge the financial support given by the DGES (Project PB97-1014. Madrid. Spain) and by DGA (Project P079/99-C, Aragon. Spain).

\section{Experimental}

\section{General}

Reaction flasks and other glassware was heated in an oven at $130^{\circ} \mathrm{C}$ overnight and assembled in a stream of Ar. All solvents were dried by the usual methods. All reactions were monitored by TLC on silica gel $60 \mathrm{~F} 254$; the position of the spots were detected with $254 \mathrm{~nm}$ UV light or by spraying with one of the following staining systems: $50 \%$ methanolic sulfuric acid, 5\% ethanolic phosphomolybdic 
acid and iodine. Preparative column chromatography was performed on columns of silica gel (60-240 mesh) and with solvents that were distilled prior to use. Preparative centrifugally accelerated radial thin-layer chromatography (PCAR-TLC) was performed with a Chromatotron ${ }^{\circledR}$ Model $7924 \mathrm{~T}$ (Harrison Research, Palo Alto, CA, USA); the rotors (1 or $2 \mathrm{~mm}$ layer thickness) were coated with silica gel Merck grade type 7749, TLC grade, with binder and fluorescence indicator (Aldrich 34,6446) and the eluting solvents were delivered by the pump at a flow-rate of $0.5-1.5 \mathrm{~mL} \mathrm{~min}^{-1}$. Melting points were uncorrected. ${ }^{1} \mathrm{H}$ and ${ }^{13} \mathrm{C}$-NMR spectra were recorded either on a Varian Unity or on a Bruker 300 instrument. Unles otherwiae mnoted chemical shifts are reported in ppm $(\delta)$ relative to $\mathrm{CHCl}_{3}(\delta=7.26)$ in $\mathrm{CDCl}_{3}$. Elemental analyses were performed on a Perkin Elmer 240B microanalyzer. Nitrone $\mathbf{2}$ was prepared as described previously by us [19].

\section{Preparation of complex 6.}

A solution of nitrone $2(1.0 \mathrm{mmol})$ in acetone, was treated with $\mathrm{ZnBr}_{2}(1.0 \mathrm{mmol})$ under an inert atmosphere and the resulting mixture was stirred for $6 \mathrm{~h}$. After this time diethyl ether was added until no more precipitation of a solid was observed. The resulting precipitate was filtered, washed with cold acetone and dried to give essentially pure complex $6(0.437 \mathrm{~g}, 100 \%)$ as a white solid; mp.: 250-252 ${ }^{\circ} \mathrm{C} ;{ }^{1} \mathrm{H}-\mathrm{NMR}$ (acetone-d $\mathrm{d}_{6}$ ) $\delta: 5.40(\mathrm{~s}, 2 \mathrm{H}), 7.41-7.45(\mathrm{~m}, 3 \mathrm{H}), 7.60-7.64(\mathrm{~m}, 2 \mathrm{H}), 8.00(\mathrm{t}, 1 \mathrm{H}, \mathrm{J}=6.2$ $\mathrm{Hz}), 8.07(\mathrm{~d}, 1 \mathrm{H}, \mathrm{J}=7.7 \mathrm{~Hz}), 8.41(\mathrm{dt}, 1 \mathrm{H}, \mathrm{J}=1.7,7.7 \mathrm{~Hz}), 8.76(\mathrm{~d}, 1 \mathrm{H}, \mathrm{J}=4.5 \mathrm{~Hz}), 8.80(\mathrm{~s}, 1 \mathrm{H}) ;{ }^{13} \mathrm{C}-$ NMR (acetone- $\mathrm{d}_{6}$ ) $\delta: 71.2,128.4,129.1$ (2C), 129.3, 129.5, 130.0, 132.8, 137.8, 141.2, 149.6; Anal Calcd. for $\mathrm{C}_{13} \mathrm{H}_{12} \mathrm{Br}_{2} \mathrm{~N}_{2} \mathrm{OZn}$ (437.45): C, 35.69; H, 2.76; N, 6.40. Found: C, 35.72; H, 2.86; N, 6.34.

General Procedure for the 1,3-dipolar cycloaddition of nitrone 2 and complex 6 with dipolarophiles 7 and 9.

The corresponding dipolarophile $(20 \mathrm{mmol})$ was added to a solution of the corresponding 1,3-dipole $(1 \mathrm{mmol})$ in acetone and the resulting solution was heated under an inert atmosphere (Ar) at reflux for the time indicated in Table 3. The mixture was cooled to ambient temperature and concentrated under reduced pressure. The cis:trans ratio of the residue was determined by ${ }^{1} \mathrm{H}-\mathrm{NMR}$ analysis and the relative stereochemistry of the adducts was determined by typical monodimensional NOE experiments. The crude material was purified by PCAR-TLC using a Chromatotron ${ }^{\circledR}(2 \mathrm{~mm}$ layer thickness).

cis-5-(Acetoxy)-2-benzyl-3-(2-pyridyl)isoxazolidine 8a. ${ }^{1} \mathrm{H}-\mathrm{NMR} \delta: 1.99(\mathrm{~s}, 3 \mathrm{H}), 2.58$ (ddd, 1H, J = 2.4, 7.8, 13.7 Hz), 3.00-3.12 (m, 1H), 4.03 (s, 2H), 4.15 (t, 1H, J = 7.8 Hz), 6.40 (dd, 1H, J = 1.9, 6.3 $\mathrm{Hz}), 7.20-7.75(\mathrm{~m}, 8 \mathrm{H}), 8.63(\mathrm{ddd}, 1 \mathrm{H}, \mathrm{J}=1.8,4.8,6.9 \mathrm{~Hz}) ;{ }^{13} \mathrm{C}-\mathrm{NMR} \delta: 21.2,44.0,60.8,69.9,95.5$, 121.8, 122.7, 127.3, 128.2, 129.1, 136.2, 136.7, 149.1, 158.7, 170.4; Anal Calcd. for $\mathrm{C}_{17} \mathrm{H}_{18} \mathrm{~N}_{2} \mathrm{O}_{3}$ (298.13):C, 68.44; H, 6.08; N, 9.39. Found: C, 68.31; H, 5.96; N, 9.16.

trans-5-(Acetoxy)-2-benzyl-3-(2-pyridyl)isoxazolidine 8b. ${ }^{1} \mathrm{H}-\mathrm{NMR} \delta: 2.06(\mathrm{~s}, 3 \mathrm{H}), 2.85(\mathrm{dd}, 1 \mathrm{H}, \mathrm{J}=$ 2.9, $7.3 \mathrm{~Hz}), 4.03(\mathrm{~s}, 2 \mathrm{H}), 4.28(\mathrm{~d}, 1 \mathrm{H}, \mathrm{J}=13.2 \mathrm{~Hz}), 4.50(\mathrm{t}, 1 \mathrm{H}, \mathrm{J}=7.8 \mathrm{~Hz}), 6.35(\mathrm{dd}, 1 \mathrm{H}, \mathrm{J}=1.9,6.5$ $\mathrm{Hz}), 7.20-7.75(\mathrm{~m}, 8 \mathrm{H}), 8.49$ (ddd, $1 \mathrm{H}, \mathrm{J}=1.9,5.1,6.8 \mathrm{~Hz}) ;{ }^{13} \mathrm{C}-\mathrm{NMR}$ 8: 21.2, 42.1, 62.4, 63.4, 97.2, 
121.1, 121.2, 127.2, 132.1, 135.1, 136.2, 136.7, 149.2, 158.8, 170.1; Anal Calcd. for $\mathrm{C}_{17} \mathrm{H}_{18} \mathrm{~N}_{2} \mathrm{O}_{3}$ (298.13): C, 68.44; H, 6.08; N, 9.39. Found: C, 68.59; H, 6.21; N, 9.44.

cis-2-Benzyl-5-(metoxycarbonyl)-3-(2-pyridyl)isoxazolidine 10a. ${ }^{1} \mathrm{H}=\mathrm{NMR} \delta: 2.81$ (ddd, $1 \mathrm{H}, \mathrm{J}=5.1$, 6.8, $12.9 \mathrm{~Hz}$ ), 3.02 (ddd, 1H, J = 8.3, 9.3, $12.9 \mathrm{~Hz}$ ), 3.64 (s, 3H), 3.99 (s, 2H), 4.15 (dd, 1H, J = 6.8, 8.3 $\mathrm{Hz}), 4.67(\mathrm{dd}, 1 \mathrm{H}, \mathrm{J}=5.1,9.3 \mathrm{~Hz}), 7.16-7.19(\mathrm{~m}, 1 \mathrm{H}), 7.19-7.26(\mathrm{~m}, 2 \mathrm{H}), 7.27-7.31(\mathrm{~m}, 1 \mathrm{H}), 7.39$ (dd, $2 \mathrm{H}, \mathrm{J}=2.1,6.7 \mathrm{~Hz}), 7.57(\mathrm{~d}, 1 \mathrm{H}, \mathrm{J}=6.8 \mathrm{~Hz}), 7.62(\mathrm{dt}, 1 \mathrm{H}, \mathrm{J}=1.7,7.2 \mathrm{~Hz}), 8.47(\mathrm{ddd}, 1 \mathrm{H}, \mathrm{J}=1.8,4.9$, $6.7 \mathrm{~Hz}) ;{ }^{13} \mathrm{C}-\mathrm{NMR} \delta: 40.1,51.9,60.4,70.3,75.1,121.7,122.5,127.1,128.1,128.3,136.7,137.0$, 148.9, 159.5, 172.0; Anal Calcd. for $\mathrm{C}_{17} \mathrm{H}_{18} \mathrm{~N}_{2} \mathrm{O}_{3}$ (298.13):C, 68.44; H, 6.08; N, 9.39. Found: C, 68.30; $\mathrm{H}, 6.18 ; \mathrm{N}, 9.32$.

trans-2-Benzyl-5-(metoxycarbonyl)-3-(2-pyridyl)isoxazolidine 10b. ${ }^{1} \mathrm{H}-\mathrm{NMR} \delta: 2.88(\mathrm{td}, 1 \mathrm{H}, \mathrm{J}=7.3$, $12.5 \mathrm{~Hz}$ ), 2.98 (ddd, $1 \mathrm{H}, \mathrm{J}=5.6,8.5,12.5 \mathrm{~Hz}), 3.70(\mathrm{~s}, 3 \mathrm{H}), 3.94$ and $4.24(2 \mathrm{~d}, 2 \mathrm{H}, \mathrm{J}=13.4 \mathrm{~Hz}), 4.33$ $(\mathrm{dd}, 1 \mathrm{H}, \mathrm{J}=5.6,7.3 \mathrm{~Hz}), 4.55(\mathrm{dd}, 1 \mathrm{H}, \mathrm{J}=7.3,8.5 \mathrm{~Hz}), 7.14-7.20(\mathrm{~m}, 1 \mathrm{H}), 7.20-7.27(\mathrm{~m}, 2 \mathrm{H}), 7.28-$ $7.32(\mathrm{~m}, 1 \mathrm{H}), 7.40(\mathrm{dd}, 2 \mathrm{H}, \mathrm{J}=1.7,8.3 \mathrm{~Hz}), 7.57(\mathrm{~d}, 1 \mathrm{H}, \mathrm{J}=8.3 \mathrm{~Hz}), 7.62(\mathrm{dt}, 1 \mathrm{H}, \mathrm{J}=1.7,7.8 \mathrm{~Hz})$,

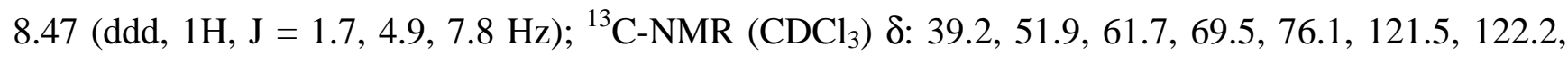
127.0, 128.0, 128.8, 136.4, 137.2, 148.8, 159.1, 172.1; Anal Calcd. for $\mathrm{C}_{17} \mathrm{H}_{18} \mathrm{~N}_{2} \mathrm{O}_{3}$ (298.13): C, 68.44; H, 6.08; N, 9.39. Found: C, 68.56; H, 5.89; N, 9.42.

cis-2-Benzyl-4-(metoxycarbonyl)-3-(2-pyridyl)isoxazolidine 10c. ${ }^{1} \mathrm{H}-\mathrm{NMR} \delta: 3.75(\mathrm{~s}, 3 \mathrm{H}), 3.98(\mathrm{td}, 1 \mathrm{H}$, $\mathrm{J}=5.3,8.3 \mathrm{~Hz}), 4.01$ and $4.09(2 \mathrm{~d}, 2 \mathrm{H}, \mathrm{J}=13.4 \mathrm{~Hz}), 4.26(\mathrm{t}, 1 \mathrm{H}, \mathrm{J}=8.3 \mathrm{~Hz}), 4.35(\mathrm{dd}, 1 \mathrm{H}, \mathrm{J}=5.3,8.3$ $\mathrm{Hz}), 4.51(\mathrm{~d}, 1 \mathrm{H}, \mathrm{J}=5.3 \mathrm{~Hz}), 7.14-7.22(\mathrm{~m}, 1 \mathrm{H}), 7.22-7.33(\mathrm{~m}, 3 \mathrm{H}), 7.37(\mathrm{dd}, 2 \mathrm{H}, \mathrm{J}=1.6,7.2 \mathrm{~Hz})$, $7.50(\mathrm{~d}, 1 \mathrm{H}, \mathrm{J}=7.8 \mathrm{~Hz}), 7.60(\mathrm{dt}, 1 \mathrm{H}, \mathrm{J}=1.6,7.7 \mathrm{~Hz}), 8.53(\mathrm{ddd}, 1 \mathrm{H}, \mathrm{J}=1.6,4.8,7.7 \mathrm{~Hz}) ;{ }^{13} \mathrm{C}-\mathrm{NMR}$ $\delta: 52.2,54.4,60.2,68.7,73.0,122.3,122.4,127.2,128.2,129.0,136.4,137.0,149.2,159.0,173.0$. Anal Calcd. for $\mathrm{C}_{17} \mathrm{H}_{18} \mathrm{~N}_{2} \mathrm{O}$ (298.13): C, 68.44; H, 6.08; N, 9.39.. Found: C, 68.32; H, 6.14; N, 9.45.

N-Benzyl-N-(phenyl-pyridin-2-yl-methyl)-hydroxylamine 13

To a cooled $\left(0^{\circ} \mathrm{C}\right)$ solution of the electrophile (nitrone 2 or complex $\left.\mathbf{6}, 1 \mathrm{mmol}\right)$ in THF $(10 \mathrm{~mL})$ was added a solution of $\mathrm{PhMgBr}(1 \mathrm{ml}$ of a $3.0 \mathrm{M}$ solution in THF, $3 \mathrm{mmol})$. The resulting solution was stirred for $2 \mathrm{~h}$ at which time a saturated solution of $\mathrm{NH}_{4} \mathrm{Cl}$ was added. The reaction mixture was diluted with diethyl ether $(20 \mathrm{~mL})$ and the organic layer was separated. The aqueous layer was extracted twice with diethyl ether; the organic extracts were combined, washed with brine, dried $\left(\mathrm{MgSO}_{4}\right)$ and evaporated under vacuum. The crude material was purified by PCAR-TLC using a Chromatotron ${ }^{\circledR}$ (1 mm layer thickness); mp.: 110-112 ${ }^{\circ} \mathrm{C} ;{ }^{1} \mathrm{H}-\mathrm{NMR} \delta: 3.70(\mathrm{~d}, 1 \mathrm{H}, \mathrm{J}=13.8 \mathrm{~Hz}), 3.90$ $(\mathrm{d}, 1 \mathrm{H}, \mathrm{J}=13.8 \mathrm{~Hz}), 5.03(\mathrm{~s}, 1 \mathrm{H}), 6.10(\mathrm{~s}, 1 \mathrm{H}), 7.11-7.65(\mathrm{~m}, 13 \mathrm{H}), 8.52(\mathrm{~d}, 1 \mathrm{H}, \mathrm{J}=4.4 \mathrm{~Hz}) ;{ }^{13} \mathrm{C}-\mathrm{NMR}$ $\delta: 61.4,73.0,122.1,122.7,127.2,127.7,128.2,128.5,128.6,129.3,136.8,138.0,140.0,148.9,161.5$. Anal Calcd. for $\mathrm{C}_{19} \mathrm{H}_{18} \mathrm{~N}_{2} \mathrm{O}$ (290.36): C, 78.59; H, 6.25; N, 9.65. Found: C, 78.56; H, 6.28; N, 9.62. 


\section{References and Notes}

1. (a) Kobayashi, S.; Busujima, T.; Nagayama, A. Novel Classification of Lewis-Acids on the Basis of Activity and Selectivity. Chem. Eur. J. 2000, 6, 3491-3494 and references cited therein. (b) Haughton, L.; Williams, J.M.J. Catalytic Applications of Transition-Metals in Organic-Synthesis. J. Chem. Soc. Perkin Trans. 1 2000, 3335-3349.

2. For a recent account see: Merino, P.; Franco, S.; Merchan, F.L.; Tejero, T. Nucleophilic additions to chiral nitrones: New approaches to nitrogenated compounds. Synlett 2000, 442-454..

3. See inter alia: (a) Merino, P.; Castillo, E. Franco, S.; Merchan, F.L.; Tejero, T. Enantiodivergent approach to D- and L-secondary N-hydroxy- $\alpha$-amino acids by using N-benzyl-2,3-Oisopropylidene-D-glyceraldehyde nitrone as an effective N-hydroxyglycine cation equivalent. $J$. Org. Chem. 1998, 63, 2371-2374. (b) Merino, P.; Franco, S.; Merchan, F.L.; Tejero, T. Diastereoselective nucleophilic addition of acetylide to N-benzyl-2,3-O-isopropylidene-Dglyceraldehyde nitrone (BIGN). Stereodivergent synthesis of $\beta$-hydroxy- $\alpha$-(hydroxyamino)- and $\beta$ hydroxy- $\alpha$-aminoacids. Tetrahedron: Asymmetry 1997, 8, 3489-3496. (c) Merino, P.; Castillo, E.; Franco, S.; Merchan, F.L.; Tejero, T. Nucleophilic additions of Grignard reagents to N-benzyl-2,3O-isopropylidene-D-glyceraldehyde nitrone (BIGN). Synthesis of (2S,3R)) and (2S,3S)-3phenylisoserine. Tetrahedron 1998, 54, 12301-12322.

4. Kanemasa, S.; Uemura, T.; Wada, E. Lewis-acid catalyzed nitrone cycloadditions to bidentate and tridentate alpha,beta-unsaturated keones. High-rate acceleration, absolutely enoselective and regioselective reactions Tetrahedron Lett. 1992, 33, 7889-7892. For a review see: Kanemasa, S.; Oderaotoshi, Y. Asymmetric cyloaddition reactions catalyzed by transition-metal complexes. New guidelines for structural design of chiral catalyst. J. Synth. Org. Chem. Jpn. 1998, 56, 368-377.

5. Kanemasa, S.; Tsururoka, T. Magnesium bromide promoted E/Z isomerization of carbonylconjugated nitrones ad highly stereoselective and regioselective cycloadditions to allylic alcohol dipolarophiles. Chem. Lett. 1995, 49-50.

6. (a) Gothelf, K.V.; Hazell, R.G.; Jorgensen, K.A. Control of diastereoselectivity and enantioselectivity in metal-catalyzed 1,3-dipolar cycloaddition reactions of nitrones with alkenes. Experimental and theoretical investigations. J. Org. Chem. 1996, 61, 346-355. (b) Gothelf, K.V.; Hazell, R.G.; Jorgensen, K.A. Molecular-sieve dependent absolute stereoselectivity in asymmetric catalytic 1,3-dipolar cycloaddition reactions. J. Org. Chem. 1998, 63, 5483-5488. (c) Jensen, K.B.; Gothelf, K.V.; Hazell, R.G.; Jorgensen, K.A. Improvement of taddolate-TiCl 2 -catalyzed 1,3dipolar nitrone cycloaddition reactions by substitution of the oxazolidinone auxiliary of the alkene with succinimide. J. Org. Chem. 1997, 62, 2471-2477.

7. Simonsen, K.B.; Bayon, P.; Hazell, R.G.; Gothelf, K.V.; Jorgensen, K.A. Catalytic enantioselective inverse-electron demand 1,3-dipolar cycloaddition reactions of nitrones with alkenes. J. Am. Chem. Soc. 1999, 121, 3845-3847.

8. Merino, P.; Anoro, S.; Merchan, F.L.; Tejero, T. 1,3-Dipolar cycloadditions of N-benzyl furfuryl nitrones with electron-rich alkenes. Molecules, 2000, 5, 132-152. 
9. (a) Tejero, T.; Dondoni, A.; Rojo, I.; Merchan, F.L.; Merino, P. 1,3-Dipolar cycloaddition of C-(2thiazolyl)nitrones to chiral acrylates. Synthesis of enantiopure $\alpha$-amino-2-alkylthiazoles and 5formylpyrrolidin-2-ones. Tetrahedron 1997, 53, 3301-3318. (b) Merino, P.; Anoro, S.; Merchan, F.L.; Tejero, T. 1,3-Dipolar cycloaddition between hetaryl nitrones and methyl acrylate: Theoretical study and application to the synthesis of functionalized pyrrolidines. Heterocycles, 2000, 53, 861-875.

10. Merino, P.; Anoro, S.; Franco, S.; Merchan, F.L.; Tejero, T.; Tuñon, V. 1,3-Dipolar cycloaddition of furfuryl nitrones with acrylates. A convenient approach to protected 4-hydroxypyroglutamic acids. J. Org. Chem. 2000, 65, 1590-1596.

11. Pierre, F.; Moinet, C.; Toupet, L. Synthesis, structure and hydrolysis of some ((eta(5)cyclopentadienyl)(eta(6)-arene)iron(II))(PF6) complexes bearing a imine or a nitrone function in $\alpha$ position of the arene ligand. J. Organomet. Chem. 1997, 527, 51-64.

12. Pierre, F.; Stricker, A.; Moinet, C.; Sinbandhit, S.; Toupet, L. Electrochemical reduction of some ((eta(5)-cyclopentadienyl)(eta(6)-arene)iron(II))(PF6) complexes bearing an imine or a nitrone function in benzylic position of the arene ligand. J. Organomet. Chem. 1998, 553, 253-267.

13. Alallaf, T.A.K.; Abdulrahman, A. Diorganotin (IV) dichloride complexes of some Narylfurfuralnitrones. Synth. React. Inorg. Metal-Org. C 1997, 27, 985-996.

14. (a) Villamena, F.A.; Dickman, M.-H.; Crist, D.R. Nitrones as ligands in complexes of $\mathrm{Cu}(\mathrm{II})$, $\mathrm{Mn}(\mathrm{II}), \mathrm{Co}(\mathrm{II}), \mathrm{Ni}(\mathrm{II}), \mathrm{Fe}(\mathrm{II})$, and $\mathrm{Fe}(\mathrm{III})$ with N-tert-butyl- $\alpha$-(2-pyridyl)nitrone and 2,5,5trimethyl-1-pyrroline-N-oxide. Inorg. Chem. 1998, 37, 1446-1453. (b) Villamena, F.A.; Crist, D.R. Metal-nitrone complexes. Spin-trapping and solution characterization. J. Chem. Soc. Dalton, Trans. 1998, 4055-4064.

15. Dickmann, M.-H.; Ward, J.P.; Villamena, F.A.; Crist, D.R. Bis( $\mu$-(N-((methylthio)phenylmethylene)-methanamine-N-oxide)-O-O)bis(bis-(1,1,1,5,5,5-hexa-fluoro-pentane-2,4dionato-O,O') nickel(II)) Acta Cryst. Sect. C Cryst. Struct. Commun. 1998, 54, 929-930.

16. Kliegel, W.; Metge, J.; Rettig, S.J.; Trotter, J. Structural Studies of Organoboron Compounds Lxviii - C-(2-Hydroxyaryl)-N-(2-Hydroxyphenylmethyl)Nitrones as Regioselective Bidentate Ligands in Boron Chelate Formation - Crystal and Molecular-Structures of a Diphenylboron Complex and Its Parent Ligand. Can. J. Chem. 1998, 76, 1082-1092.

17. Purchased from Aldrich (P6,200-3) and distilled prior to use

18. Borch, R.F.; Berstein, M.D.; Durst, M.D. The cyanoborohydridoborate anion as a selective reducing agent. J. Am. Chem. Soc. 1971, 93, 2897-2904.

19. Dondoni, A.; Franco, S.; Junquera, F.; Merchan, F.L.; Merino, P.; Tejero, T. Synthesis of N-benzyl nitrones. Synth. Commun. 1994, 24, 2537-2550.

20. Merino, P.; Anoro, S.; Tejero, T.; Laguna, M.; Cerrada, E.; Moreno, A. unpublished results.

21. Siemens XSCANS. X-Ray Single Crystal Analysis System. Copyright (C) 1992 by SIEMENS. Siemens analytical X-ray instruments Inc. Madison, Wisconsin. USA

22. SIR-97. A Package for Crystal Structure Solution by Direct Methods and Refinement. Giacovazzo et al. 1997

23. SHELXL-97. Program for the Refinement of Crystal Structures. Sheldrick, G. M. 1997. 
24. PovChem v. 2.1. Copyright (C) 1999 by Paul A. Thiessen.

25. Gaussian 98, Revision A.3, M. Frisch, J.; Trucks, G. W.; Schlegel, H. B.; Scuseria, G. E.; Robb, M. A.; Cheeseman, J. R.; Zakrzewski, V. G.; Montgomery Jr., J. A.; Stratmann, R. E.; Burant, J. C.; Dapprich, S.; Millam, J. M.; Daniels, A. D.; Kudin, K. N.; Strain, M. C.; Farkas, O.; Tomasi, J.; Barone, V.; Cossi, M.; Cammi, R.; Mennucci, B.; Pomelli, C.; Adamo, C.; Clifford, S.; Ochterski, J.; Petersson, G. A.; Ayala, P. Y.; Cui, Q.; Morokuma, K.; Malick, D. K.; Rabuck, A. D.; Raghavachari, K.; Foresman, J. B.; Cioslowski, J.; Ortiz, J. V.; Stefanov, B. B.; Liu, G.; Liashenko, A.; Piskorz, P.; Komaromi, I.; Gomperts, R.; Martin, R. L.; Fox, D. J.; Keith, T.; AlLaham, M. A.; Peng, C. Y.; Nanayakkara, A.; Gonzalez, C.; Challacombe, M.; Gill, P. M. W.; Johnson, B.; Chen, W.; Wong, M. W.; Andres, J. L.; Gonzalez, C.; Head-Gordon, M.; Replogle, E. S. and Pople, J. A. Gaussian, Inc., Pittsburgh PA, 1998.

26. CS ChemOffice. Copyright (C) 1997 by Cambridge Soft Corporation. Cambridge, MA. USA

Samples Availability: Samples of compounds $\mathbf{2}$ and $\mathbf{6}$ are available from MDPI.

(C) 2001 by Molecular Diversity Preservation International (MDPI) 